cured by the use of galvanism. I think there can be little donbt that galvanism was the chief instrument in the recovery of my case, and so far this contrasts with the experience of Dr. Althaus, who, in his recent interesting papers on anosmia, asserts that the strength of current necessary to excite the olfactory nerve is too great to be borne by the patient. In these cases the injury appears to be caused not to the olfactory centre, which Dr. Ferrier localises in the subicular region, but to the olfactory nerve, by contrecoup. In the cases relieved by potassium iodide there may be a sub-inflammatory condition of the nerve membranes ; but in the cases cured by galvanism we must suppose a long disused nerve path forced by the strong stimulus of the exciting current.

\section{PARACENTESIS CRANII IN CASES OF HYDROCEPHALUS.}

BY HUGH P. DUNN, F.R.C.S.,

CLINICAL ASSISTANT TO THE ROYAL SOUTH LONDON OPHTHALMIC HOSPITAL, LATE HOUSE SURGEON TO THE BELGRAVE HOSPITAL FOR CHILDREN, ETC.

THE disfavour which formerly belonged to this operation was doubtless owing to the belief that the risks associated with its performance were not outweighed by the benefits which it was sought to produce. But, in these times, when the adaptation of apparatus to the necessities of a special case is a matter of no difficulty, and improvements various and of much import have been effected in surgical instruments, it may be said that the risks of surgery have been reduced, in certain cases at least, by the introduction of special instruments. Not only have operations been rendered less risky, but their performance has been made easier, and the outcome of the introduction of a special instrument for a certain case has frequently been that this same instrument has been found useful in the treatment of totally different cases. Now there is so much difference in the manner in which surgical interference is tolerated by various structures, that the idiosyncrasies of each with regard to this demand the cureful attention of the surgeon. Having learnt in what peculiarity the intolerance of a certain structure to surgical interference consists, it is then necessary with the facts before us to meet the difficulties of the case with what ever means may be available for the purpose. For as experience alone can teach us the extent to which structures will not resent operative treatment, so also experience can only teach us the means to render them tolerant. The results, for instance, of ahdominal surgery distinctly show that whereas peritonitis after such an operation as ovariotony is rare, its occurrence is always to be expected when the peritoneum has been wounded by external violence. Again, the tolerance of injury which recorded cases have shown of the brain membranes as well as of the brain substanceitself prompts the assurance that much of it is owing to the means adopted of obviating the effects of the violence upon the tissues concerned. The rule of surgery which requires the removal of splintered and loose portions of bone in compound fractures of the skull is as important as that which requires the thorough cleansing of the peritoneal cavity after operations upon the abdomen. The enforcement of these rules is imperative, and their adoption is advantageous, inasmuch as results have shown the importance of their observance; and the principle involved, though similar in each, is one to which surgeons are ever ready to acknowledge their allegiance when cases arise in which its application may seem to be demanded. If, then, surgery has progressed in recent times, some progress at least has been owing to the improvement effected in surgical appliances, to the knowledge obtained of the tolerance of the tissues, and of the means to render them tolerant.

A small aspirator of about half an ounce capacity, furnished with a double cock arrangement, is the most convenient for the performance of paracentesis cranii. The utility of a small aspirator is that it can be easily handled, and the needle when within the cranium well controlled. In addition to which the withdrawal of the fluid is made necessarily very gradual. The child being held on the nurse's lap, with its head facing the light, the surgeon marks a point in the situation of the coronal suture about an inch from the longitudinal sinus, and, holding the needle firmly in his right hand, thrusts it into the cranium, with its point slightly inclined inwards. It is of course necessary to insist upon the perfect working of the apparatus before the operation is commenced, and the plan is a good one first of all thoroughly to cleanse the needle in a carbolic-acid solution. The needle having entered the cranium, the surgeon grasps it close to the scalp between the forefinger and thumb of the left hand, and steadies the head with the right, and the assistant manipulates the piston of the aspirator. The piston should be slowly withdrawn, and pauses of a few seconds now and again allowed to elapse in a manner similar to the application of the écraseur. The cylinder of the aspirator being full, the cocks are altered and the fluid injected into a clean bottle. Thus the process is continued until no more fluid can be obtained, or until that which flows is seen to be turbid. The position of the needle may, from time to time, be altered, according as the tension on the piston of the aspirator shows that the fluid has diminished. After the extraction of about half an ounce of fluid compression of the cranium should be secured. There are several ways of doing this, and one of the best is to use a piece of india-rubber tubing corresponding in diameter to a quarter-inch gas-pipe. Continuous pressure is thus maintained, and it can be altered at will by relaxing or tightening the tube. The use of any form of roller is unserviceable, owing to its liability to slip out of position, and the difficulty which is experienced in controlling the pressure. The tube, around which some lint may be wrapped or sewed, should be made to encircle the cranium twice at a level of the occipital protuberance behind, and the centre of the forehead in front. As the fluid is gradually withdrawn the tube is, from time time, readjusted and tightened. The operation having been completed, the punctured spot is then covered with a piece of dry lint, and attention directed to the compression of the cranium. This may be maintained by fixing the tube in situ, or a capeline bandage of flannel answers the purpose, if carefully applied. It is necessary, during the operation, occssionally to note the effect, if any, upon the child. The condition of the pulse would be the guide as to the judiciousness or not of continuing the operation, and in the event of any pallor supervening, the administration of a little brandy with water after the operation is indicated.

To sum up-l. Paracentesis cranii is indicated in all cases of acute and chronic hydrocephalus in which, medicinal treatment having failed, the patient is clearly suffering from the increase of the fluid, and life is threatened.

2. It is the only means by which life can be prolonged, even if, by its performance, the disease is not arrested.

3. All the fluid which can be obtained should be withdrawn.

4. The operation may be required to be repeated should a re-collection of the fluid be followed by a return of the symptoms which rendered its previous performance necessary.

5. The risks associated with the operation are almost nil, if carefully performed.

I may add that Messrs. Wright, of New Bond-street, have an aspirator of the form and capacity to which I have referred. Hinde-street, Manchester-square.

\section{OBSCURE CHRONIC EPIGASTRIC PAIN IN A PERSON APPARENTLY OTHERWISE HEALTHY;}

SUDDEN AND RAPIDLY FATAL HAMORRHAGE FROM STOMACH AND BOWELS ; AUTOPSY ; DUODENAL ULCER.

\section{BY EDW. B. GRAY, M.D. OxoN.}

J. J- age fifty-eight, a retired college servant, between 5 and 6 P.M. on Sept. 24th suddenly vomited a large quantity of blood. On my arrival about a quarter of an hour afterwards, I found he had brought up by measure over twenty ounces of bright-red blood. $\mathrm{He}$ was ordered twenty minims of tincture of perchloride of iron every three hours, to keep to ice and iced water, and to remain absolutely at rest on his back.

He was a very well-nourished man, and of healthy appearance. I could find no evidence of disease of heart, liver, or kidneys. The appetite was normal; epigastrium 